\title{
Tumor-targeting Salmonella typhimurium A1-R in combination with doxorubicin eradicate soft tissue sarcoma in a patient- derived orthotopic xenograft (PDOX) model
}

\author{
Takashi Murakami ${ }^{1,2,3}$, Jonathan DeLong ${ }^{2}$, Fritz C. Eilber ${ }^{5}$, Ming Zhao ${ }^{1}$, Yong Zhang ${ }^{1}$, \\ Nan Zhang ${ }^{1}$, Arun Singh ${ }^{4}$, Tara Russell ${ }^{5}$, Samantha Deng ${ }^{1}$, Jose Reynoso ${ }^{1}$, Cuong \\ Quan $^{1}$, Yukihiko Hiroshima ${ }^{3}$, Ryusei Matsuyama ${ }^{3}$, Takashi Chishima ${ }^{3}$, Kuniya \\ Tanaka $^{3}$, Michael Bouvet ${ }^{2}$, Sant Chawla ${ }^{6}$, Itaru Endo ${ }^{3}$ and Robert M. Hoffman ${ }^{1,2}$ \\ ${ }^{1}$ AntiCancer, Inc., San Diego, California, USA \\ 2 Department of Surgery, University of California, San Diego, California, USA \\ ${ }^{3}$ Department of Gastroenterological Surgery, Graduate School of Medicine, Yokohama City University, Yokohama, Japan \\ ${ }^{4}$ Division of Hematology-Oncology, University of California, Los Angeles, California, USA \\ ${ }^{5}$ Division of Surgical Oncology, University of California, Los Angeles, California, USA \\ ${ }^{6}$ Sarcoma Oncology Center, Santa Monica, California, USA \\ Correspondence to: Robert M. Hoffman, email: all@anticancer.com
}

Fritz C. Eilber, email: fceilber@mednet.ucla.edu

Keywords: nude mice, patient-derived orthotopic xenograft, soft tissue sarcoma, Salmonella typhimurium A 1-R, tumor-targeting Received: January 12,2016 Accepted: January 27, $2016 \quad$ Published: February 07, 2016

\section{ABSTRACT}

A patient with high grade undifferentiated pleomorphic soft-tissue sarcoma from a striated muscle was grown orthotopically in the right biceps femoris muscle of mice to establish a patient-derived orthotopic xenograft (PDOX) model. Twenty PDOX mice were divided into 4 groups: G1, control without treatment; G2, Salmonella typhimurium (S. typhimurium) A1-R administered by intratumoral (i.t.) injection once a week for 4 weeks; G3, doxorubicin (DOX) administered by intraperitoneal (i.p.) injection once a week for 4 weeks; G4, S. typhimurium A1-R (i.t.) administered once a week for 2 weeks followed by i.p. doxorubicin once a week for 2 weeks. On day 25 from the initiation of treatment, tumor volume in G2, G3, and G4 was significantly lower than G1. Mice found without gross tumor included one mouse (20\%) in G2; one mouse (20\%) in G3; and 3 mice (60\%) in G4. Body weight loss did not significantly differ between the 3 treated groups or from the untreated control. Histological examination revealed eradication of tumor only in $\mathbf{6 4}$ where mice were treated with S. typhimurium A1-R followed by DOX. Our present study indicates future clinical potential of combining S. typhimurium A1-R with chemotherapy such as DOX for soft tissue sarcoma patients.

\section{INTRODUCTION}

For soft-tissue sarcoma, the 5-year survival for patients with metastatic disease is less than $20 \%[1,2]$. Doxorubicin (DOX) treatment for advanced soft tissue sarcoma resulted in a median survival of only 18 months. Therefore, development of improved treatment is needed.

Records for almost 300 years have documented cancer patients going into remission after a bacterial infection if they survived the infection [3]. For example, in 1867 , Busch reported that a malignant tumor disappeared when the patient contracted what is now known as Streptococcus pyogenes [4].

In the late nineteenth century, William B. Coley at Memorial Hospital in New York, the precursor of Memorial Sloan-Kettering Cancer Center, treated cancer patients with $S$. pyogenes. Coley's first patient infected with $S$. pyogenes recovered from head and neck cancer. Coley injected many cancer patients with $S$. pyogenes and often had good results [3].

Salmonella typhimurium (S. typhimurium), is a facultative anaerobe which confers important advantages 
Table 1: Treatment response between groups

\begin{tabular}{|c|c|c|c|c|c|c|}
\hline & \multicolumn{5}{|c|}{ Histological response (Evans grading system) } & \multirow[b]{2}{*}{$\mathbf{C R}$} \\
\hline & Grade I & Grade IIA & Grade IIB & Grade III & Grade IV & \\
\hline G1 $(n=5)$ & 5 & 0 & 0 & 0 & 0 & 0 \\
\hline $\mathrm{G} 2(\mathrm{n}=5)$ & 0 & 2 & 2 & 0 & 0 & 1 \\
\hline $\mathrm{G} 3(\mathrm{n}=5)$ & 1 & 2 & 0 & 0 & 1 & 1 \\
\hline $\mathrm{G} 4(\mathrm{n}=5)$ & 0 & 0 & 0 & 2 & 0 & 3 \\
\hline
\end{tabular}

G1: Untreated control

G2: S. typhimurium A1-R-alone

G3: Doxorubicin-alone

G4: S. typhimurium A1-R followed by doxorubicin

as a potential cancer therapeutic, in that a facultative anaerobe can grow in the oxic viable region of tumors as well as necrotic regions [5]. In a Phase I clinical trial on patients with metastatic melanoma and renal carcinoma, the S. typhimurium strain tested (VNP20009), attenuated by $\mathrm{msbB}$ and purI mutations, was safely administered to patients [6].

The tumor-targeting $S$. typhimurium A1-R strain developed by our laboratory has higher tumor-colonization efficacy and antitumor efficacy than S. typhimuriumVNP20009 [7], possibly because it has fewer attenuation mutations. S. typhimurium A1-R is auxotrophic for Leu-Arg, which prevents it from mounting a continuous infection in normal tissues. S. typhimurium A1-R was able to inhibit or eradicate primary and metastatic tumors as monotherapy in nude mouse models of prostate $[8,9]$, breast [10-12], lung [13, 14], pancreatic [15-19], ovarian $[20,21]$ stomach [22], and cervical cancer [23], as well as sarcoma cell lines [24-26] and glioma [27, 28], all of which are highly aggressive tumor models.

Previously, we developed a patient-derived orthotopic xenograft (PDOX) nude-mouse model of softtissue sarcoma. The sarcoma was resistant to gemcitabine. Pazopanib tended to reduce the tumor volume compared to the untreated mice, but there was no significant difference. However, S. typhimurium A1-R significantly inhibited tumor growth compared to the untreated mice. These results suggest tumor-targeting $S$. typhimurium A1-R is a promising treatment for chemo-resistant soft-tissue sarcoma [29].

A human patient with advanced leiomyosarcoma was treated with an intratumoral injection of Clostridium novyi $(C$. novyi-NT) spores which reduced the tumor within and surrounding the bone [30].

Since S. typhimurium A1-R is a facultative anaerobe, unlike C. novyi-NT, which is an obligate anaerobe, it was thought to have more broad application for cancer therapy. In addition, since $S$. typhimurium A1-R can greatly potentiate cytotoxic chemotherapy and the fact that DOX is first-line therapy for soft tissue sarcoma, it was appropriate to determine the efficacy of $S$. typhimurium A1-R followed by DOX in a PDOX model of soft tissue sarcoma compared to either therapy alone.

\section{RESULTS AND DISCUSSION}

\section{Effects of single agent and combined $S$. typhimurium A1-R and DOX on sarcoma PDOX growth}

On the $25^{\text {th }}$ day from initiation of treatment, tumor volume was significantly smaller in the animals treated with $S$. typhimurium A1-R (G2) $\left(245.3 \pm 141.6 \mathrm{~mm}^{3}\right.$, $p<0.01)$; the animals treated with DOX (G3) $(165.5 \pm$ $247.7 \mathrm{~mm}^{3}, p<0.05$ ); and the animals treated with $S$. typhimurium A1-R followed by DOX (G4) (138.4 \pm 209.3 $\left.\mathrm{mm}^{3}, p<0.01\right)$ compared to the untreated control animals (G1) $\left(1460.3 \pm 1136.6 \mathrm{~mm}^{3}\right.$, Figure 2). There were no significant differences in tumor volume between G2, G3, and G4. One tumor in G2, 1 tumor in G3, and 3 tumors in G4 achieved complete remission (no detectable tumor). Mouse body weight did not significantly differ between the 3 treatment groups, and the treatment groups did not significantly differ in body weight from the untreated control group. Since the tumor diameter in G1 reached $20 \mathrm{~mm}$ after the $25^{\text {th }}$ treatment day, all mice in G1 were sacrificed by the $29^{\text {th }}$ day.

\section{Histological response to chemotherapy}

Tumors were mainly comprised of viable spindle shaped cells in the tumors from the untreated animals (G1) (Figure. 3A, 3B). In G2 treated with S. typhimurium A1-R forty to $60 \%$ of the tumor tissue consisted of viable tissue (Grade IIA or IIB), whereas the other part was replaced by necrosis or inflammatory cells (Figure 3C, 3D). The response of tumors treated with DOX alone (G3) varied widely; one tumor showed no necrosis (Grade I; Figure $3 \mathrm{E}$ ), two tumors had a small amount of necrosis (Grade IIA), and the other tumor was necrotic without viable cells (Grade IV; Figure 3F). The two tumors which did not undergo complete remission in G4 were comprised of large areas of necrosis or inflammation (Grade III; Figure $3 \mathrm{G}, 3 \mathrm{H}$ ). Tumors in $\mathrm{G} 4$, treated with the combination of S. typhimurium A1-R followed by DOX were considered 
A

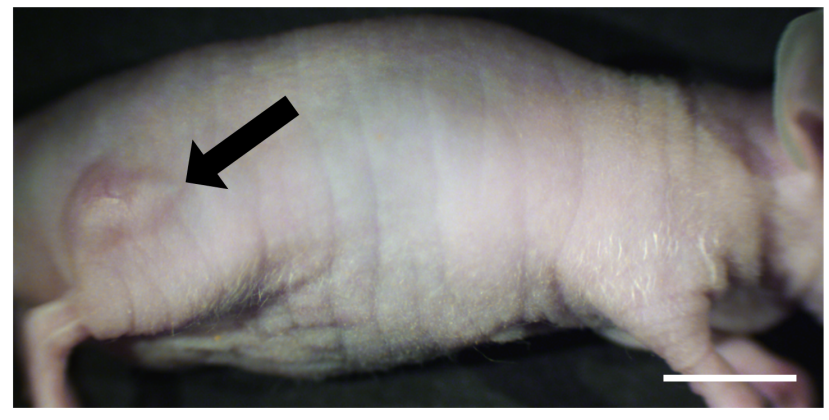

B

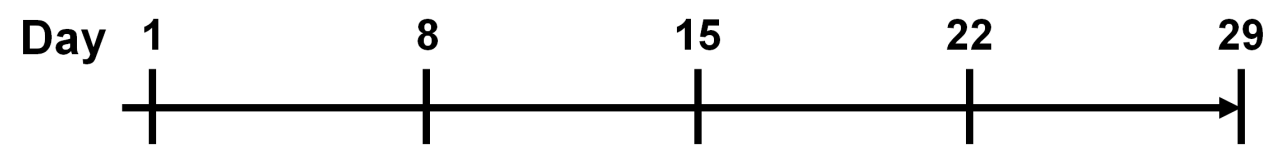

G1

No treatment

G2

\begin{tabular}{|l|l|l|}
\hline $\mathrm{A} 1-\mathrm{R}$ & $\mathrm{A} 1-\mathrm{R} 1-\mathrm{R}$ & $\mathrm{A} 1-\mathrm{R}$ \\
\hline
\end{tabular}

G3

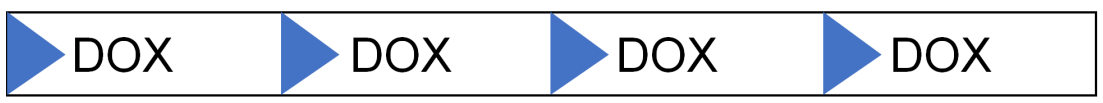

G4

\begin{tabular}{|l|l|}
\hline $\mathrm{A} 1-\mathrm{R}$ & $\mathrm{A} 1-\mathrm{R}$ \\
\hline
\end{tabular}

Figure 1: Treatment model and protocol. A. Soft tissue sarcoma PDOX mouse model. Ten days after surgical orthotopic implantation (SOI), tumors in the right biceps femoris muscle had grown more than $5 \mathrm{~mm}$ in diameter. Arrow indicates a grown tumor. Scale bar: $10 \mathrm{~mm}$. B. Treatment protocol. G1: untreated control; G2: treated with S. typhimurium A1-R (A1-R)-alone (i.t., $5 \times 10^{7} \mathrm{CFU} /$ body, weekly, 4 weeks) G3: treated with doxorubicin (DOX)-alone (i.p., $3 \mathrm{mg} / \mathrm{kg}$, weekly, 4 weeks); G4: treated with $S$. typhimurium A1-R (i.t., $5 \times 10^{7} \mathrm{CFU} / \mathrm{body}$, weekly, 2 weeks) followed by DOX (i.p., $3 \mathrm{mg} / \mathrm{kg}$, weekly, 2 weeks). Each group contained 5 mice.

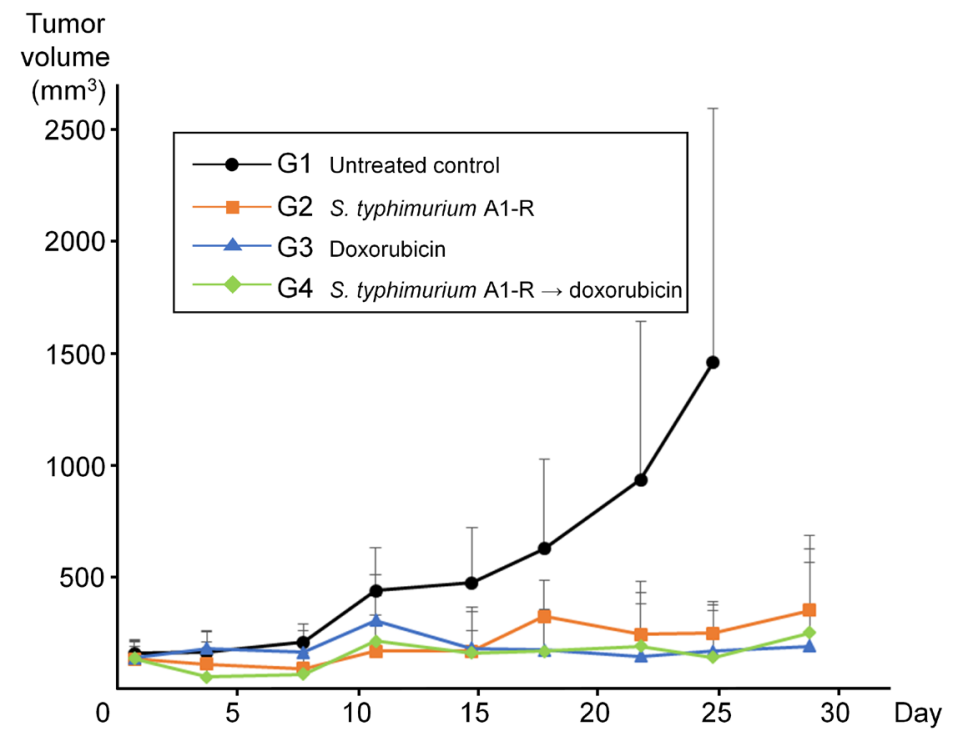

Figure 2: S. typhimurium and A1-R doxorubicin or their combination significantly inhibited tumor growth in a soft tissue sarcoma PDOX model. Graph shows tumor volume at each time point. On day 25 from initial treatment, tumor volume in G2 (S. typhimurium A1R-alone) $\left(245.3 \pm 141.6 \mathrm{~mm}^{3}, p<0.01\right)$; G3 (DOX-alone) $\left(165.5 \pm 247.7 \mathrm{~mm}^{3}, p<0.05\right)$; and G4 (S. typhimurium A1-R followed by DOX) $\left(138.4 \pm 209.3 \mathrm{~mm}^{3}, p<0.01\right)$ was significantly smaller than in G1. There was not a significant difference between the treated groups. Error bars: +1 SD. 
eradicated. These results were summarized in Table 1.

Recently we established a soft tissue sarcoma PDOX model in which the mouse-grown tumors more closely recapitulated the human histology, as compared to xenografts [31] implanted subcutaneously. This may be a general phenomenon for all tumor types [32].

The higher rate eradication of tumors by the combination of $S$. typhimurium and DOX may be attributable to the "decoy" effect of S. typhimurium A1-R [33], which induces quiescent cells to cycle, there by making them more susceptible to chemotheraphy than when the cancer cells are in $\mathrm{G}_{1} / \mathrm{G}_{0}$ which are the majority of cells in a solid tumor [34]. Future experiments will investigate this possibility.

\section{G1 \\ Untreated control}

\section{G2 \\ S. typhimurium A1-R}

\section{G3 \\ Doxorubicin}

\section{G4 \\ S. typhimurium A1-R \\ $+$ Doxorubicin}
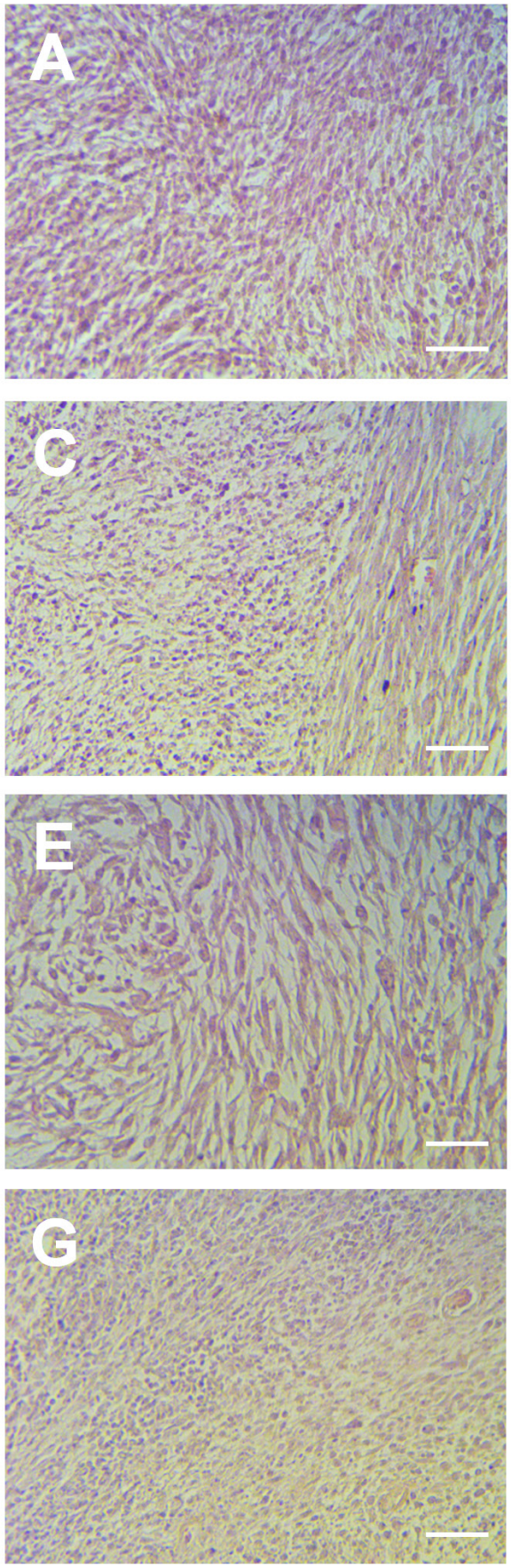
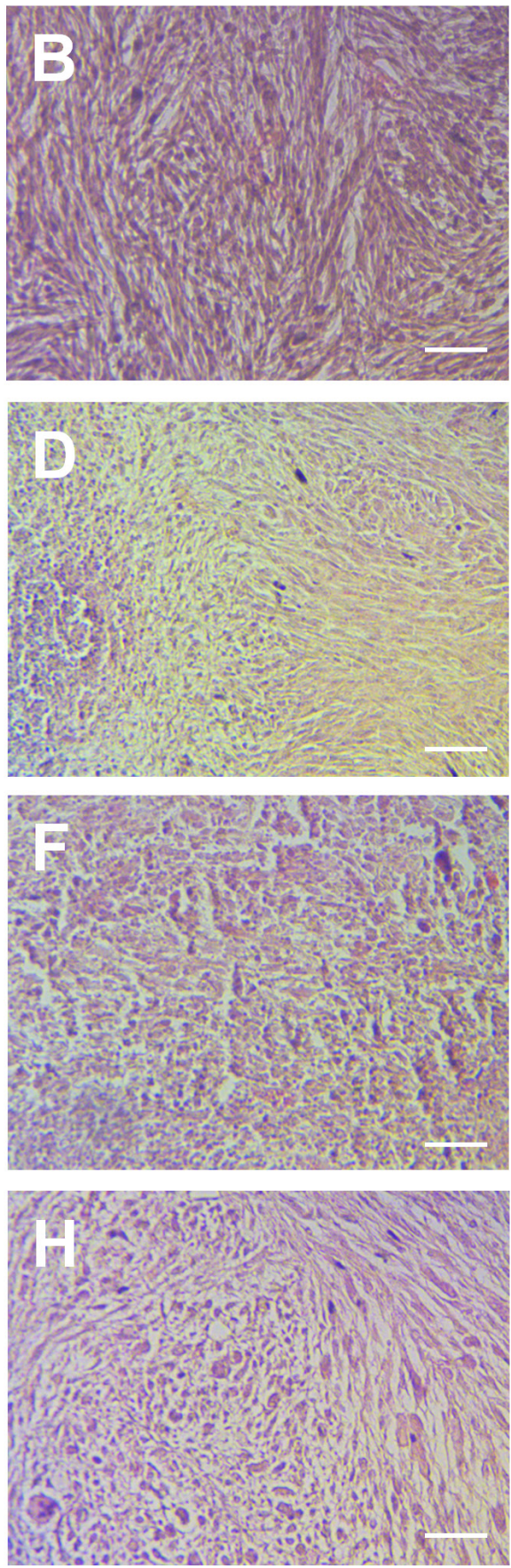

Figure 3: Histological response. Untreated tumors (G1) were comprised of spindle-shaped viable sarcomatous cells without necrosis or inflammatory change A. B. Tumors treated with S. typhimurium A1-R (G2) had components of inflammation (C. Grade IIB), or necrosis (D. Grade IIA). One of the tumors treated with doxorubicin (DOX) (G3) showed no necrosis (E. Grade I), while another tumor showed complete tumor necrosis (F. Grade IV). Tumors treated with the combination of S. typhimurium A1-R and DOX were destroyed and replaced with inflammatory-type cells (G. H. Grade III). Hematoxylin and eosin staining. Scale bars: $100 \mu \mathrm{m}$. 
Recently, Roberts et al. [30] treated a patient with advanced leiomyosarcoma with spores of the obligate anaerobe $C$. novyi-NT. A single metastasis was injected with the C. novyi-NT spore and appeared to be completely destroyed. The patient died due to other lesions of the leiomyosarcoma. The fact that $C$. novyi-NT is an obligate anaerobe may preclude its systemic administration and may limit its treatment to i.t. injection. This should not be the case for the facultative anaerobe $S$. typhimurium A1-R, where we have shown in previous experiments to be effective against tumors when administered i.v. Although, i.t. administration of S. typhimurium A1-R was used in the present experiment as a model for clinical testing, future treatment of soft tissue sarcoma will utilize i.v. administration as well. Future experiments will test simultaneous treatment of S. typhimurium A1-R and DOX to determine synergy.

\section{CONCLUSIONS}

The combination of $S$. typhimurium A1-R and subsequent DOX eradicated a soft tissue sarcoma in a PDOX mouse model. In the early part of the $20^{\text {th }}$ century, bacterial therapy of sarcoma was first-line therapy under William B. Coley at the Memorial Hospital of New York. Since DOX is presently considered first-line therapy of soft tissue sarcoma, the combination of DOX with $S$. typhimurium A1-R has important future clinical potential, which we hope can be realized in the near future. Another potential future clinical strategy is to combine sarcoma surgery with adjuvant $S$. typhimurium A1-R which we have shown to be highly effective in mouse models [35].

\section{MATERIALS AND METHODS}

\section{Mice}

Athymic $n u / n u$ nude mice (AntiCancer Inc., San Diego, CA), 4-6 weeks old, were used in this study. All animal studies were conducted with an AntiCancer Institutional Animal Care and Use Committee (IACUC)protocol specifically approved for this study and in accordance with the principals and procedures outlined in the National Institute of Health Guide for the Care and Use of Animals under Assurance Number A3873-1. In order to minimize any suffering of the animals, the use of anesthesia and analgesics were used for all surgical experiments. Animals were anesthetized by subcutaneous injection of a $0.02 \mathrm{ml}$ solution of $20 \mathrm{mg} / \mathrm{kg}$ ketamine, 15.2 $\mathrm{mg} / \mathrm{kg}$ xylazine, and $0.48 \mathrm{mg} / \mathrm{kg}$ acepromazine maleate. The response of animals during surgery was monitored to ensure adequate depth of anesthesia. The animals were observed on a daily basis and humanely sacrificed by $\mathrm{CO}_{2}$ inhalation when they met the following humane endpoint criteria: severe tumor burden (more than 20 $\mathrm{mm}$ in diameter), prostration, significant body weight loss, difficulty breathing, rotational motion and body temperature drop. Animals were housed in a barrier facility on a high efficiency particulate arrestance (HEPA)-filtered rack under standard conditions of 12-hour light/dark cycles. The animals were fed an autoclaved laboratory rodent diet.

\section{Patient-derived tumor}

A large right thigh high-grade undifferentiated pleomorphic sarcoma was resected by F.C.E., Division of Surgical Oncology, University of California, Los Angeles (UCLA). The patient did not receive any chemotherapy or radiotherapy prior to surgery. Written informed consent was obtained from the patient as part of a UCLA Institutional Review Board (IRB \#10-001857) approved protocol.

\section{Establishment of a PDOX model of soft tissue sarcoma by surgical orthotopic implantation (SOI)}

A fresh sample of a soft tissue sarcoma which had grown in striated muscle of a patient was obtained and transported immediately to the laboratory at AntiCancer, Inc., on wet ice. The sample was cut into 5-mm fragments and implanted subcutaneously in nude mice. After three weeks, the subcutaneously-implanted tumors grew to more than $10 \mathrm{~mm}$ in diameter. The subcutaneouslygrown tumors were then harvested and cut into small fragments $\left(3 \mathrm{~mm}^{3}\right)$. After the mice were anesthetized with the ketamine solution described above, a 5-mm skin incision was made on the right high thigh into the biceps femoris, which was split to make space for the sarcoma tissue fragment. A single tumor fragment was implanted orthotopically into the space to establish the PDOX model. The wound was closed with a 6-0 nylon suture (Ethilon, Ethicon, Inc., NJ, USA).

\section{Preparation and administration of $S$. typhimurium A1-R}

GFP-expressing $S$. typhimurium A1-R bacteria (AntiCancer, Inc., San Diego, CA, USA) were grown overnight on LB medium and then diluted 1:10 in LB medium. Bacteria were harvested at late-log phase, washed with PBS, and then diluted in PBS. S. typhimurium A1-R was injected intratumorally. A total of $5 \times 10^{7} \mathrm{CFU}$ S. typhimurium A1-R in $50 \mu \mathrm{l}$ PBS was administered to each tumor. 


\section{Treatment study design in the PDOX model of soft tissue sarcoma}

Ten days after orthotopic implantation, tumors reached $5 \mathrm{~mm}$ in diameter (Figure 1A). Twenty PDOX model mice were randomized into 4 groups of 5 mice each (Figure 1B): G1, control without treatment; G2, treated with S. typhimurium A1-R; i.t. once a week for 4 weeks; $\mathrm{G} 3$, treated with $3 \mathrm{mg} / \mathrm{kg}$ doxorubicin (pfizer, NewYork, NY,) i.p. once a week for 4 weeks, G4: treated with $S$. typhimurium A1-R (i.t.) once a week for 2 weeks followed by doxorubicin i.p. once a week for 2 weeks. Tumor length, width and mouse body weight were measured twice in a week. Tumor volume was calculated with the following formula: Tumor volume $\left(\mathrm{mm}^{3}\right)=$ length $(\mathrm{mm})$ $\times$ width $(\mathrm{mm}) \times$ width $(\mathrm{mm}) \times 1 / 2$. Data are presented as mean \pm SD. When a tumor was not detectible, the tumor response was considered as complete remission. All treated mice were sacrificed on day 29 , and tumors were resected for further histological evaluation.

\section{Histological examination}

Fresh tumor samples were fixed in $10 \%$ formalin and embedded in paraffin before sectioning and staining. Tissue sections $(5 \mu \mathrm{m})$ were deparaffinized in xylene and rehydrated in an ethanol series. Hematoxylin and eosin ( $\mathrm{H} \& \mathrm{E})$ staining was performed according to standard protocol. Histological examination was performed with a BHS System Microscope (Olympus Corporation, Tokyo, Japan). Images were acquired with INFINITY ANALYZE software (Lumenera Corporation, Ottawa, Canada). Histological response was evaluated according to the Evans grading system that had been developed for human-cancer histological-response evaluation after chemo-radiotherapy [36]. Briefly, histological response was classified as follows; Grade I: no or little $(<10 \%)$ cancer-cell destruction; Grade IIA: 10-49\% cancer-cell destruction; Grade IIB: 50-89\% cancer cell destruction; Grade III: few $(<10 \%)$ viable cancer cells are present, Grade IV: no viable tumor is detectible.

\section{Statistical analysis}

SPSS statistics version 21.0 was used for all statistical analyses (IBM, New York City, NY, USA). Significant differences for continuous variables were determined using the Mann-Whitney U test. A probability value of $P<0.05$ was considered statistically significant.

\section{Dedication}

This paper is dedicated to the memory of A. R. Moossa, M.D. and Sun Lee, M.D.

\section{CONFLICTS OF INTEREST}

M.Z., Y.Z., N.Z., J.R., and C.Q. are employees of AntiCancer Inc. T.M., S.D. and R.M.H. are unsalaried associates of AntiCancer Inc. There are no other competing financial interests.

\section{REFERENCES}

1. http://www.cancer.org/cancer/sarcomaadultsofttissuecancer/detailedguide/sarcoma-adult-softtissue-cancer-survival-rates.

2. Nystrom LM, Reimer NB, Reith JD, Dang L, Zlotecki RA, Scarborough MT, Gibbs CP Jr. Multidisciplinary management of soft tissue sarcoma. Scientific World Journal 2013; 28:852462.

3. William Coley. Available from: http://en.wikipedia.org/ wiki/William_Coley [Last accessed 12 December 2015]

4. Forbes NS. Engineering the perfect (bacterial) cancer therapy. Nat Rev Cancer 2010; 10:785-94.

5. Pawelek JM, Low KB, Bermudes D. Bacteria as tumourtargeting vectors. Lancet Oncol 2003; 4:548-56.

6. Toso JF, Gill VJ, Hwu P, Marincola FM, Restifo NP, Schwartzentruber DJ, Sherry RM, Topalian SL, Yang JC, Stock F, Freezer LJ, Morton KE, Seipp C, Haworth L, Mavroukakis S, White D, MacDonald S, Mao J, Sznol M, Rosenberg SA. Phase I study of the intravenous administration of attenuated Salmonella typhimurium to patients with metastatic melanoma. J Clin Oncol 2002; 20:142-52.

7. Zhang Y, Zhang N, Zhao M, Hoffman RM. Comparison of the selective targeting efficacy of Salmonella typhimurium A1-R and VNP20009 on the Lewis lung carcinoma in nude mice. Oncotarget 2015; 6:14625-14631. doi: 10.18632/ oncotarget.3342.

8. Zhao M, Yang M, Li XM, Jiang P, Baranov E, Li S, Xu M, Penman S, Hoffman RM. Tumor-targeting bacterial therapy with amino acid auxotrophs of GFP-expressing Salmonella typhimurium. Proc Natl Acad Sci USA 2005; 102:755-760.

9. Zhao M, Geller J, Ma H, Yang M, Penman S, Hoffman RM. Monotherapy with a tumor-targeting mutant of Salmonella typhimurium cures orthotopic metastatic mouse models of human prostate cancer. Proc Natl Acad Sci USA 2007; 104:10170-10174.

10. Zhao M, Yang M, Ma H, Li X, Tan X, Li S, Yang Z, Hoffman RM. Targeted therapy with a Salmonella typhimurium leucine-arginine auxotroph cures orthotopic human breast tumors in nude mice. Cancer Res 2006; 66:7647-7652.

11. Zhang Y, Tome Y, Suetsugu A, Zhang L, Zhang N, Hoffman RM, Zhao M. Determination of the optimal route of administration of Salmonella typhimurium A1-R to target breast cancer in nude mice. Anticancer Res 2012; 32:2501-2508. 
12. Zhang Y, Miwa S, Zhang N, Hoffman RM, Zhao M. Tumor-targeting Salmonella typhimurium A1-R arrests growth of breast-cancer brain metastasis. Oncotarget 2015; 6:2615-2622. doi: 10.18632/oncotarget.2811.

13. Uchugonova A, Zhao M, Zhang Y, Weinigel M, König K, Hoffman RM. Cancer-cell killing by engineered Salmonella imaged by multiphoton tomography in live mice. Anticancer Res 2012; 32:4331-4339.

14. Liu F, Zhang L, Hoffman RM, Zhao M. Vessel destruction by tumor-targeting Salmonella typhimurium A1-R is enhanced by high tumor vascularity. Cell Cycle 2010; 9:4518-4524.

15. Nagakura C, Hayashi K, Zhao M, Yamauchi K, Yamamoto N, Tsuchiya H, Tomita K, Bouvet M, Hoffman RM. Efficacy of a genetically-modified Salmonella typhimurium in an orthotopic human pancreatic cancer in nude mice. Anticancer Res 2009; 29:1873-1878.

16. Yam C, Zhao M, Hayashi K, Ma H, Kishimoto H, McElroy M, Bouvet M, Hoffman RM. Monotherapy with a tumortargeting mutant of S. typhimurium inhibits liver metastasis in a mouse model of pancreatic cancer. J Surg Res 2010; 164:248-255.

17. Hiroshima Y, Zhao M, Zhang Y, Maawy A, Hassanein MK, Uehara F, Miwa S, Yano S, Momiyama M, Suetsugu A, Chishima T, Tanaka K, Bouvet M, Endo I , Hoffman RM. Comparison of efficacy of Salmonella typhimurium A1-R and chemotherapy on stem-like and non-stem human pancreatic cancer cells. Cell Cycle 2013; 12:2774-2780.

18. Hiroshima Y, Zhao M, Maawy A, Zhang Y, Katz MH, Fleming JB, Uehara F, Miwa S , Yano S, Momiyama M, Suetsugu A, Chishima T, Tanaka K, Bouvet M, Endo I, Hoffman RM. Efficacy of Salmonella typhimurium A1-R versus chemotherapy on a pancreatic cancer patient-derived orthotopic xenograft (PDOX). J Cell Biochem 2014; 115:1254-1261.

19. Hiroshima Y, Zhang Y, Murakami T, Maawy AA, Miwa S, Yamamoto M, Yano S, Sato S, Momiyama M, Mori R, Matsuyama R, Chishima T, Tanaka K, et al. Efficacy of tumor-targeting Salmonella typhimurium A1-R in combination with anti-angiogenesis therapy on a pancreatic cancer patient-derived orthotopic xenograph (PDOX) and cell line mouse models. Oncotarget 2014; 5:12346-12357. doi: 10.18632/oncotarget.2641.

20. Matsumoto Y, Miwa S, Zhang Y, Hiroshima Y, Yano S, Uehara F, Yamamoto M, Toneri M, Bouvet M, Matsubara H, Hoffman RM, Zhao M. Efficacy of tumor-targeting Salmonella typhimurium A1-R on nude mouse models of metastatic and disseminated human ovarian cancer. J Cell Biochem 2014; 115:1996-2003.

21. Matsumoto Y, Miwa S, Zhang Y, Zhao M, Yano S, Uehara F, Yamamoto M, Hiroshima Y, Toneri M, Bouvet M, Matsubara H, Tsuchiya H, Hoffman RM. Intraperitoneal administration of tumor-targeting Salmonella typhimurium A1-R inhibits disseminated human ovarian cancer and extends survival in nude mice. Oncotarget 2015; 6:11369-
11377. doi: 10.18632/oncotarget.3607.

22. Yano S, Zhang Y, Zhao M, Hiroshima Y, Miwa S, Uehara F, Kishimoto H, Tazawa H, Bouvet M, Fujiwara T, and Hoffman RM. Tumor-targeting Salmonella typhimurium A1-R decoys quiescent cancer cells to cycle as visualized by FUCCI imaging and become sensitive to chemotherapy. Cell Cycle 2014; 13:3958-3963.

23. Hiroshima Y, Zhang Y, Zhao M, Zhang N, Murakami T, Maawy A, Mii S, Uehara F, Yamamoto M, Miwa S, Yano S, Momiyama M, Mori R, Matsuyama R, Chishima T, Tanaka K, Ichikawa Y, Bouvet M, Endo I, Hoffman RM. Tumor-targeting Salmonella typhimurium A1-R in combination with Trastuzumab eradicates HER-2-positive cervical cancer cells in patient-derived mouse models. PLoS One 2015; 10: e0120358.

24. Hayashi K, Zhao M, Yamauchi K, Yamamoto N, Tsuchiya H, Tomita K, Hoffman RM. Cancer metastasis directly eradicated by targeted therapy with a modified Salmonella typhimurium. J Cell Biochem 2009; 106:992-998.

25. Hayashi K, Zhao M, Yamauchi K, Yamamoto N, Tsuchiya H, Tomita K, Kishimoto H, Bouvet M, Hoffman RM. Systemic targeting of primary bone tumor and lung metastasis of high-grade osteosarcoma in nude mice with a tumor-selective strain of Salmonella typhimurium. Cell Cycle 2009; 8:870-875.

26. Miwa S, Zhang Y, Baek K-E, Uehara F, Yano S, Yamamoto M, Hiroshima Y, Matsumoto Y, Kimura H, Hayashi K, Yamamoto N, Bouvet M, Tsuchiya H, Hoffman RM, Zhao M. Inhibition of spontaneous and experimental lung metastasis of soft-tissue sarcoma by tumor-targeting Salmonella typhimurium A1-R. Oncotarget 2014; 5:1284912861. doi: 10.18632/oncotarget.2561.

27. Kimura H, Zhang L, Zhao M, Hayashi K, Tsuchiya H, Tomita K, Bouvet M, Wessels J, Hoffman RM. Targeted therapy of spinal cord glioma with a genetically-modified Salmonella typhimurium. Cell Proliferation 2010; 43:41-48.

28. Momiyama M, Zhao M, Kimura H, Tran B, Chishima T, Bouvet M, Endo I, Hoffman RM. Inhibition and eradication of human glioma with tumor-targeting Salmonella typhimurium in an orthotopic nude-mouse model. Cell Cycle 2012; 11:628-632.

29. Hiroshima Y, Zhao M, Zhang Y, Zhang N, Maawy A, Murakami T, Mii S, Uehara F, Yamamoto M, Miwa S, Yano S, Momiyama M, Mori R,Matsuyama R, Chishima T, Tanaka K, Ichikawa Y, Bouvet M, Endo I, Hoffman RM. Tumor-targeting Salmonella typhimurium A1-R arrests a chemo-resistant patient soft-tissue sarcoma in nude mice. PLoS One 2015; 10: e0134324.

30. Roberts NJ, Zhang L, Janku F, Collins A, Bai RY, Staedtke V, Rusk AW, Tung D, Miller M, Roix J, Khanna KV,Murthy R, Benjamin RS, Helgason T, Szvalb AD, Bird JE, RoyChowdhuri S, Zhang HH, Qiao Y, Karim B,McDaniel J, Elpiner A, Sahora A, Lachowicz J, Phillips B, Turner A, Klein MK, Post G, Diaz LA Jr, Riggins GJ, Papadopoulos N, Kinzler KW, Vogelstein B, Bettegowda 
C, Huso DL, Varterasian M, Saha S, Zhou S. Intratumoral injection of Clostridium novyi-NT spores induces antitumor responses. Sci Transl Med 2014; 6:249ra111.

31. Hiroshima Y, Zhang Y, Zhang N, Uehara F, Maawy A, Murakami T, Mii S, Yamamoto M, Miwa S, Yano S, Momiyama M, Mori R, Matsuyama R,Chishima T, Tanaka K, Ichikawa Y, Bouvet M, Endo I, Hoffman RM. Patientderived orthotopic xenograft (PDOX) nude mouse model of soft-tissue sarcoma more closely mimics the patient behavior in contrast to the subcutaneous ectopic model. Anticancer Res 2015; 35:697-701.

32. Hoffman RM. Patient-derived orthotopic xenografts: better mimic of metastasis than subcutaneous xenografts. Nature Reviews Cancer 2015; 15:451-452.

33. Yano S, Zhang Y, Zhao M, Hiroshima Y, Miwa S, Uehara F, Kishimoto H, Tazawa H, Bouvet M, Fujiwara T, Hoffman RM. Tumor-targeting Salmonella typhimurium A1-R decoys quiescent cancer cells to cycle as visualized by FUCCI imaging and become sensitive to chemotherapy. Cell Cycle 2014; 13:3958-3963.

34. Yano S, Zhang Y, Miwa S, Tome Y, Hiroshima Y, Uehara F, Yamamoto M, Suetsugu A, Kishimoto H, Tazawa H, Zhao M, Bouvet M, Fujiwara T,Hoffman RM. Spatial-temporal FUCCI imaging of each cell in a tumor demonstrates locational dependence of cell cycle dynamics and chemoresponsiveness. Cell Cycle 2014; 13:2110-2119.

35. Murakami T, Hiroshima Y, Zhao M, Zhang Y, Chishima T, Tanaka K, Bouvet M, Endo I, Hoffman RM. Adjuvant treatment with tumor-targeting Salmonella typhimurium A1-R reduces recurrence and increases survival after liver metastasis resection in an orthotopic nude mouse model. Oncotarget 2015; 6: 41856-41862. doi: 10.18632/ oncotarget.6170.

36. Evans DB, Rich TA, Byrd DR, Cleary KR, Connelly JH, Levin B, Charnsangavej C, Fenoglio CJ, Ames FC. Preoperative chemoradiation and pancreaticoduodenectomy for adenocarcinoma of the pancreas. Arch Surg 1992; 127:1335-1339. 